\title{
Comparison of Characteristics between Frequent Participants and Non-Participants in Screening Program for Stomach Gancer
}

\author{
Akira Fukao ${ }^{1}$, Shigeru Hisamichi ${ }^{1}$, Shoko Komatsu ${ }^{1}$, \\ Hiroyuki Shimizu ${ }^{2}$, Hiroshi Satoh ${ }^{3}$, Haruo \\ Nakatsuka $^{3}$, Takao Watanabe ${ }^{4}$, Susumu Fujisaku ${ }^{5}$, \\ Yoshimi Ichinowatari ${ }^{6}$, Satoru Kuroda ${ }^{7}$, Yasuo Ida ${ }^{7}$, \\ Seiki Suda ${ }^{8}$, Kunio Kato ${ }^{9}$ and Masayuki Ikeda ${ }^{10}$ \\ ${ }^{1}$ Department of Public Health, Tohoku University School of \\ Medicine, Sendai 980, ${ }^{2}$ Department of Public Health, Gifu \\ University School of Medicine, Gifu 500, ${ }^{3}$ Department of \\ Environmental Health Sciences, Tohoku University School \\ of Medicine, Sendai 980, ${ }^{4}$ Miyagi College of Education, \\ Sendai 980, ${ }^{5}$ The Regional Health Care Information Center \\ of Miyagi Prefecture, Sendai 980, ${ }^{6}$ Department of Health, \\ Iwate Prefecture, Morioka 020, ${ }^{7}$ Department of Health and \\ Environment, Miyagi Prefecture, Sendai 980, ${ }^{8}$ Department \\ of Health, Sendai City, Sendai 980, ${ }^{9}$ Sendai City Health \\ and Welfare Foundation, Sendai 980, and ${ }^{10}$ Department of \\ Public Health, Kyoto University Faculty of Medicine, \\ Kyoto 606
}

Fukao, A., Hisamichi, S., Komatsu, S., Shimizu, H., Satoh, H., Nakatsuka, H., Watanabe, T., Fujisaku, S., Ichinowatari, Y., Kuroda, S., Ida, Y., Suda, S., Kato, K. and IKeda, M. Comparison of Characteristics between Frequent Participants and Non-Participants in Screening Program for Stomach Cancer. Tohoku J. Exp. Med., 1992, 166 (4), 459-469 — To clarify the differences in characteristics between participants and non-participants in the screening program for stomach cancer, life-style and medical histories were compared among 20, 169 subjects who lived in an urban area (Sendai) and a rural area (Wakuya and Tajiri) in Miyagi Prefecture, Japan. All subjects were classified into three groups according to the frequency of participation in the screening program during the last 5 years ; i.e., frequent participating group (FPG) for 4 or 5 times, reference group (RG) for 13 times and non-participating group (NPG) for 0 times. Subjects in the FPG consumed more milk and green-yellow vegetable whereas those in the NPG consumed less these foods. The age-adjusted proportions of present smokers were higher in the NPG but lower in the FPG significantly. The proportions of subjects who had parental histories of all cancers and stomach cancer and past

Received February 5, 1992 ; revision accepted for publication March 26, 1992.

Reprint requests to: Akira Fukao, Department of Public Health, Tohoku University School of Medicine, 2-1 Seiryomachi, Aoba-ku, Sendai 980, Japan. 
history of gastro-duodenal ulcer were higher in the FPG and lower in the NPG. To control influences among the variables a stepwise multiple regression analysis was done, and it revealed that smoking and parental history of cancers were strong predictors to explain the frequency of participation._—_ life style; screening; stomach cancer

In Japan stomach cancer has had the highest mortality of all cancers. To prevent for stomach cancer death the screening program using double contrast radiography was started around 1960 (Hirayama et al. 1985). This program was recognized as effective in this country (Ohshima et al. 1986 ; Fukao et al. 1987 ; Hisamichi et al. 1988) and was included in the Health and Medical Services Law for the Aged 1982. One of the most urgent problems of this program, however, is how to raise coverage rate. In 1988 the coverage rate of this program was only $11.9 \%$ of the target population under the law, whereas the Ministry of Health and Welfare set a goal as high as $30 \%$. In order to raise coverage rate of the program it is essential to clarify the differences of characteristics between participants and non-participants.

This study was undertaken to elucidate these differences in the residents of urban and rural areas in Miyagi Prefecture, Japan.

\section{Materials and Methods}

\section{Subjects}

The details of the subjects surveyed were described previously (Ikeda et al. 1986; Nakatsuka et al. 1988). But briefly, 11, 315 residents of Sendai (urban area) and 8,854 of Wakuya and Tajiri (rural area), whose ages were 40 to 79 , responded to self-completion questionnaire.

The subjects were classified into three groups according to the frequency of participation in the screening program for stomach cancer during the previous 5 years; i.e., the frequent participating group (FPG), the reference group ( $R G$ ) and non-participating group (NPG) consisted of subjects who participated 4 or 5, 1-3 and 0 times, respectively.

\section{Methods}

Items analyzed in this study were consumption of foods, teas, coffee and alcohol, smoking habit, parental medical histories and past medical histories. Except for rice each of 10 food items were classified into 5 frequency categories (almost everyday, 3-4 days per week, 1-2 days per week, 1-2 days per month and none) and the proportions of subjects in the highest quintile (almost everyday) were calculated. Rice intake was questioned as number of cups per day, and the proportion of subjects whose intake were more than 6 cups per day was calculated. Teas (Japanese tea and black tea) and coffee intake were classified into 5 frequency categoreies (5 or more cups per day, 3-4 cups per day, 1-2 cups per day, sometimes and none), and the proportion of subjects in the two highest quintile ( 3 or more cups per day) was calculated. Alcohol habit was classified into 5 categories (daily, occasional, sociable, former and non-drinkers) and the proportion of daily drinkers was calculated. Smoking habit was classified into 3 categories (smokers, ex-smokers and nonsmokers) and the proportion of present smokers was calculated. As items pertaining to the parental histories, cerebrovascular disease, heart disease, all cancers and stomach cancer, were selected and the proportion of positive subjects was calculated for each disease. As items of past histories, 10 diseases (hypertension, cerebrovascular disease, heart disease, 
diabetes, liver disease, gastro-duodenal ulcer, gallstone, appendicitis, tuberculosis, pneumonia) were included and proportions of subjects having these histories were calculated for each disease.

All proportions among 3 participation groups by sex and area were adjusted for age using the Japanese census population of 1985 . The differences in the age-adjusted proportions for each item between the NPG and the RG, and between the FPG and the RG were statistically tested by Mantel-Haenszel $\chi^{2}$ test.

Furthermore to control influences among the variables a stepwise multiple regression analysis was conducted. In this analysis the dependent variable was the number of times of participation during the last 5 years. The independent variables were all variables examined above and they, except for the age, were coded 1 if the individual had the factor and 0 if not. The criteria whether the individual had the factor or not were the same as used in calculating proportions. The value in years itself was assigned to the variable of age. In all statistical analyses ASP (ADVANCED STATISTICAL PACKAGE, NEC Corporation 1984) was used.

\section{RESULTS}

\section{Distribution of subjects by sex, age and area}

The distribution of the total 20,169 subjects are shown in Table 1. In the urban group the proportions of the NPG were the highest and those of the FPG

TABLE 1. Distribution of subjects

\begin{tabular}{cccrrr}
\hline $\begin{array}{c}\text { Group of } \\
\text { participation }\end{array}$ & $\begin{array}{c}\text { Age } \\
\text { (years) }\end{array}$ & NPG $^{\mathrm{a}}(\%)$ & $\mathrm{RG}^{\mathrm{b}}(\%)$ & $\mathrm{FPG}^{\mathrm{c}}(\%)$ & Total (\%) \\
\hline Urban group & $40-49$ & $851(46.5)$ & $554(30.3)$ & $425(23.2)$ & $1830(100)$ \\
(male) & $50-59$ & $607(34.7)$ & $529(30.3)$ & $611(35.0)$ & $1747(100)$ \\
& $60-69$ & $451(39.0)$ & $419(36.3)$ & $285(24.7)$ & $1155(100)$ \\
& $70-79$ & $262(42.6)$ & $242(39.3)$ & $111(18.0)$ & $615(100)$ \\
& Total & $2171(40.6)$ & $1744(32.6)$ & $1432(26.8)$ & $5347(100)$ \\
Rural group & $40-49$ & $296(23.6)$ & $648(51.6)$ & $311(24.8)$ & $1255(100)$ \\
(male) & $50-59$ & $319(21.0)$ & $705(46.4)$ & $496(32.6)$ & $1520(100)$ \\
& $60-69$ & $175(20.1)$ & $411(47.2)$ & $285(32.7)$ & $871(100)$ \\
& $70-79$ & $105(23.0)$ & $192(42.0)$ & $160(35.0)$ & $457(100)$ \\
& Total & $895(21.8)$ & $1956(47.7)$ & $1252(30.5)$ & $4103(100)$ \\
Urban group & $40-49$ & $982(51.3)$ & $704(36.7)$ & $230(12.0)$ & $1916(100)$ \\
(female) & $50-59$ & $728(36.3)$ & $839(41.8)$ & $441(22.0)$ & $2008(100)$ \\
& $60-69$ & $512(38.3)$ & $558(41.8)$ & $266(19.9)$ & $1336(100)$ \\
& $70-79$ & $332(46.9)$ & $278(39.3)$ & $98(13.8)$ & $708(100)$ \\
& Total & $2554(42.8)$ & $2379(39.9)$ & $1035(17.3)$ & $5968(100)$ \\
Rural group & $40-49$ & $306(21.9)$ & $752(53.8)$ & $340(24.3)$ & $1398(100)$ \\
(female) & $50-59$ & $311(18.2)$ & $859(50.3)$ & $539(31.5)$ & $1709(100)$ \\
& $60-69$ & $241(22.5)$ & $503(47.0)$ & $327(30.5)$ & $1071(100)$ \\
& $70-79$ & $196(34.2)$ & $232(40.5)$ & $145(25.3)$ & $573(100)$ \\
& Total & $1054(22.2)$ & $2346(49.4)$ & $1351(28.4)$ & $4751(100)$ \\
\hline
\end{tabular}

${ }^{a}$ Non-participating group ; ${ }^{b}$ Reference group ; ${ }^{c}$ Frequent participating group. 
were the lowest in both sexes and among almost all the age groups. On the contrary the proportions of the FPG were higher than those of the NPG in the rural group in almost all the age groups. The proportion of the NPG was two-folds higher in the urban group than in the rural group.

\section{Foods, teas and coffee, alcohol and smoking}

The age-adjusted proportions of the subjects in the three participation groups by sex and area are shown in Tables 2 and 3 . The items of which the ageadjusted proportions were lower in the NPG and higher in the FPG than in the $R G$ consistently among all the subgroups were milk and green-yellow vegetables. Except for the FPG in the female urban group, the differences of proportions in milk were statistically significant. The differences of proportions in green-yellow vegetables were significant for the FPG in the male urban group, and for the NPG in the female rural group $(p<0.05)$. On the contrary the age-adjusted proportions of present smokers were higher in the NPG and lower in the FPG consistently among all the subgroups. The differences were statistically significant for the FPG in the male urban and rural groups $(p<0.01)$, and for the NPG in the female urban $(p<0.05)$ and rural $(p<0.01)$ groups.

As far as the other food items were concerned, several age-adjusted propor-

TABLE 2. Age-adjusted proportions of subjects in studied items (Male)

\begin{tabular}{lrrrrrr}
\hline \multirow{2}{*}{ Group of participation } & \multicolumn{3}{c}{ Urban group } & \multicolumn{3}{c}{ Rural group } \\
\cline { 2 - 7 } & $\mathrm{NPG}^{\mathrm{a}}$ & $\mathrm{RG}$ & $\mathrm{FPG}^{\mathrm{c}}$ & $\mathrm{NPG}$ & $\mathrm{RG}$ & $\mathrm{FPG}$ \\
\hline Rice ( $\geqq 6$ cups/day) & 8.1 & 7.5 & 7.1 & 25.6 & 26.5 & 23.8 \\
Bread (everyday) & 23.0 & 23.8 & 24.5 & 7.9 & 5.8 & 7.6 \\
Meat (everyday) & 20.1 & 21.1 & 21.4 & 17.4 & 17.9 & 21.3 \\
Fish (everyday) & 36.6 & 34.5 & 36.7 & 46.8 & 50.1 & 49.4 \\
Egg (everyday) & 28.1 & 30.7 & 30.6 & 38.8 & 39.2 & 39.5 \\
Milk (everyday) & $35.9^{*}$ & 39.4 & $47.0^{* *}$ & $31.6^{*}$ & 35.5 & $44.8^{* *}$ \\
Green-yellow vegetables (everyday) & 49.1 & 49.8 & $53.7^{*}$ & 45.0 & 48.2 & 49.6 \\
Other vegetables (everyday) & 60.4 & 58.6 & $62.3^{*}$ & 66.6 & 69.6 & 71.8 \\
Fruits (everyday) & 48.2 & 50.9 & $55.4^{*}$ & $51.8^{*}$ & 56.0 & 54.9 \\
Miso soup (everyday) & 82.5 & 81.7 & 81.0 & 92.6 & 91.0 & 92.3 \\
Japanese pickles (everyday) & 59.5 & 58.8 & 56.7 & 74.4 & 78.5 & 76.4 \\
Japanese tea ( $\geqq 3$ cups/day) & 62.9 & 61.7 & $67.1^{* *}$ & 61.2 & 62.9 & 62.8 \\
Black tea ( $\geqq 3$ cups/day) & 1.4 & 1.9 & 1.0 & 0.9 & 1.9 & 1.2 \\
Coffee ( $\geqq 3$ cups/day) & 15.6 & 15.9 & 14.2 & $8.5^{* *}$ & 5.8 & 8.2 \\
Alcohol (everyday) & 49.8 & 46.9 & 47.8 & 47.3 & 46.5 & 43.6 \\
Smoking (present) & 56.0 & 51.8 & $45.4^{* *}$ & 63.0 & 56.0 & $49.6^{* *}$ \\
\hline
\end{tabular}

${ }^{\mathrm{a} N o n-p a r t i c i p a t i n g ~ g r o u p ; ~}{ }^{\mathrm{b}}$ Reference group ; ${ }^{\mathrm{c}} \mathrm{Frequent}$ participating group.

${ }^{*} p<0.05,{ }^{* *} p<0.01$ (Mantel-Haenszel $\chi^{2}$ test; NPG vs. RG and FPG vs. RG) 
TABLE 3. Age-adjusted proportions of subjects in studied tiems (Female)

\begin{tabular}{lcccccc}
\hline \multirow{2}{*}{ Group of participation } & \multicolumn{3}{c}{ Urban group } & \multicolumn{3}{c}{ Rural group } \\
\cline { 2 - 7 } & $\mathrm{NPG}^{\mathrm{a}}$ & $\mathrm{RG}^{\mathrm{b}}$ & $\mathrm{FPG}$ & $\mathrm{NPG}$ & $\mathrm{RG}$ & $\mathrm{FPG}$ \\
\hline Rice ( $\geqq$ 6 cups/day) & 2.3 & 2.0 & 1.7 & 9.5 & 8.5 & 7.6 \\
Bread (everyday) & 28.7 & 28.0 & 26.9 & 7.8 & 5.8 & 7.6 \\
Meat (everyday) & 21.8 & 23.9 & 25.3 & $15.1^{*}$ & 18.1 & $21.9^{*}$ \\
Fish (everyday) & 36.6 & 38.8 & $42.9^{*}$ & $44.6^{*}$ & 48.9 & 49.2 \\
Egg (everyday) & $28.4^{* *}$ & 32.0 & 28.3 & $29.9^{*}$ & 34.2 & 34.3 \\
Milk (everyday) & $38.7^{* *}$ & 43.6 & 46.2 & $30.1^{* *}$ & 38.2 & $43.4^{* *}$ \\
Green-yellow vegetables (everyday) & 61.4 & 62.8 & 65.6 & $49.6^{*}$ & 54.6 & 57.9 \\
Other vegetables (everyday) & 70.9 & 72.5 & 74.2 & $73.5^{*}$ & 77.5 & 80.0 \\
Fruits (everyday) & $72.7^{*}$ & 75.9 & 77.3 & 72.3 & 75.5 & 77.7 \\
Miso soup (everyday) & 80.1 & 81.0 & 82.4 & 91.5 & 92.2 & 92.8 \\
Japanese pickles (everyday) & 64.0 & 65.4 & 64.0 & 82.8 & 83.1 & 83.4 \\
Japanese tea ( $\geqq 3$ cups/day) & 63.0 & 68.3 & 69.0 & $68.5^{* *}$ & 61.5 & 62.4 \\
Black tea ( $\geqq 3$ cups/day) & 1.7 & 2.2 & 1.6 & 0.9 & 2.0 & 0.7 \\
Coffee ( $\geqq 3$ cups/day) & $9.4^{* *}$ & 6.6 & 7.7 & 5.4 & 4.5 & 3.6 \\
Alcohol (everyday) & 6.0 & 5.2 & 4.7 & $4.1^{*}$ & 2.5 & 2.5 \\
Smoking (present) & $12.0^{*}$ & 9.6 & 8.7 & $8.3^{* *}$ & 4.7 & 3.2 \\
\hline
\end{tabular}

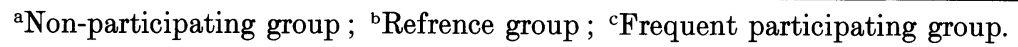

${ }^{*} p<0.05,{ }^{* *} p<0.01$ (Mantel-Haenszel $\chi^{2}$ test; NPG vs. RG and FPG vs. RG)

tions were higher or lower in specific participation groups, but no consistencies were observed among different subgroups.

\section{Parental medical histories}

The relationship between participation and the parental medical histories is showen in Table 4 and 5. The age-adjusted proportions of subjects whose parents had histories of cerebrovascular disease or heart disease tended to be lower among the NPG. The age-adjusted proportions of subjects with parental histories of cancers or stomach cancer were lower in the NPG among all the subgroups, and higher in the FPG in the female urban and rural groups, of which differences were statistically significant in most cases.

\section{Past medical histories}

Table 6 and 7 show the relationship between participation and past medical histories. The age-adjusted proportions of subjects with histories of cerebrovascular disease tended to be higher in the NPG and lower in the FPG. The proportions of subjects with history of gastro-duodenal ulcer were significantly higher in the FPG and lower in the NPG among almost all subgroups. The subjects with history of appendicitis tended to be higher in the FPG. There were 
TABLE 4. Age-adjusted proportions of subjects with parental medical histories (Male)

\begin{tabular}{ccccccc}
\hline \multirow{2}{*}{ Group of participation } & \multicolumn{3}{c}{ Urban Group } & \multicolumn{3}{c}{ Rural group } \\
\cline { 2 - 7 } & $\mathrm{NPG}^{\mathrm{a}}$ & $\mathrm{RG}^{\mathrm{b}}$ & $\mathrm{FPG}^{\mathrm{c}}$ & $\mathrm{NPG}$ & $\mathrm{RG}$ & $\mathrm{FPG}$ \\
\hline Cerebrovascular disease & & & & & & \\
Father & 21.8 & 23.0 & 23.0 & 25.2 & 28.8 & 26.6 \\
Mother & 16.2 & 16.6 & 16.5 & 19.3 & 21.8 & 19.6 \\
Heart cisease & & & & & & \\
Father & 10.5 & 9.9 & 9.7 & $11.7^{* *}$ & 15.9 & 17.7 \\
Mother & 8.5 & 9.7 & 10.4 & 12.8 & 14.3 & 13.3 \\
All cancers & & & & & & \\
Father & $13.6^{*}$ & 16.2 & 15.3 & $12.2^{*}$ & 15.9 & 17.7 \\
Mother & 13.4 & 13.1 & 14.3 & $9.3^{*}$ & 12.2 & 13.5 \\
Stomach cancer & & & & & & \\
Father & $7.5^{*}$ & 9.7 & 8.4 & $7.3^{* *}$ & 11.3 & 13.6 \\
Mother & 4.5 & 5.7 & 5.9 & $4.1^{*}$ & 5.8 & 8.0 \\
\hline
\end{tabular}
group.

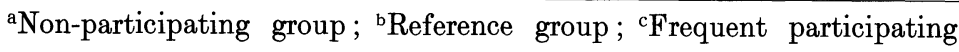
$\mathrm{RG})$

${ }^{*} p<0.05,{ }^{* *} p<0.01$ (Mantel-Haenszel $\chi^{2}$ test; NPG vs. RG and FPG vs.

TABLE 5. Age-adjusted proportions of subjects with parental medical histories (Female)

\begin{tabular}{clccccc}
\hline \multirow{2}{*}{ Group of participation } & \multicolumn{3}{c}{ Urban group } & \multicolumn{3}{c}{ Rural group } \\
\cline { 2 - 7 } & $\mathrm{NPG}^{\mathrm{a}}$ & $\mathrm{RG}^{\mathrm{b}}$ & $\mathrm{FPG}^{\mathrm{c}}$ & $\mathrm{NPG}$ & $\mathrm{RG}$ & $\mathrm{FPG}$ \\
\hline $\begin{array}{c}\text { Cerebrovascular disease } \\
\text { Father }\end{array}$ & $20.4^{* *}$ & 25.0 & $20.7^{*}$ & 27.5 & 29.2 & 29.4 \\
Mother & 15.8 & 17.5 & 16.4 & $17.2^{* *}$ & 23.7 & 21.0 \\
Heart disease & & & & & & \\
Father & 10.6 & 11.6 & 9.7 & 8.5 & 10.0 & 11.7 \\
Mother & 12.1 & 10.5 & 12.9 & $10.3^{*}$ & 14.0 & 14.6 \\
All cancers & & & & & & \\
Father & 14.4 & 15.4 & $22.0^{* *}$ & $11.8^{* *}$ & 16.2 & 19.1 \\
Mother & $10.1^{* *}$ & 14.4 & $18.8^{*}$ & 11.9 & 11.6 & 13.3 \\
Stomach cancer & & & & & & \\
Father & 8.6 & 9.8 & $12.8^{*}$ & 8.6 & 9.8 & $13.3^{*}$ \\
Mother & $4.3^{* *}$ & 6.6 & 6.3 & 5.7 & 6.6 & $9.2^{*}$ \\
\hline
\end{tabular}
group.

${ }^{a}$ Non-participating group; ${ }^{\mathrm{b}}$ Reference group; ${ }^{\mathrm{c}}$ Frequent participating $\mathrm{RG)}$

${ }^{*} p<0.05,{ }^{* *} p<0.01$ (Mantel-Haenszel $\chi^{2}$ test ; NPG vs. RG and FPG vs. 
TABLE 6. Age-adjusted proportions of subjects with past medical histories (Male)

\begin{tabular}{lcrrrrr}
\hline \multirow{2}{*}{ Group of participation } & \multicolumn{3}{c}{ Urban group } & \multicolumn{3}{c}{ Rural group } \\
\cline { 2 - 7 } & NPG & RG & FPG & NPG & RG & FPG \\
\hline Hypertension & 24.6 & 24.0 & $26.9^{*}$ & 30.7 & 27.5 & 28.4 \\
Cerebrovasular disease & 1.3 & 1.1 & $0.4^{*}$ & $2.4^{* *}$ & 0.9 & 0.7 \\
Heart disease & 8.8 & 8.1 & 8.1 & 7.2 & 8.5 & 8.2 \\
Diabetes & 9.2 & 9.3 & 8.9 & 5.9 & 6.0 & 6.3 \\
Liver disease & 5.9 & 6.9 & 7.0 & 6.8 & 6.5 & 7.3 \\
Gastro-duodenal ulcer & $12.6^{*}$ & 15.0 & 15.4 & $11.5^{* *}$ & 16.4 & $20.5^{* *}$ \\
Gall stone & 3.0 & 3.1 & 2.9 & 1.5 & 1.9 & 1.8 \\
Appendicitis & 7.0 & 6.0 & 7.5 & 6.3 & 5.1 & $8.1^{* *}$ \\
Tuberculosis & 8.4 & 7.3 & 7.8 & 4.7 & 3.0 & 3.3 \\
Pneumonia & 2.2 & 2.1 & 2.6 & 2.1 & 1.7 & 1.8 \\
\hline
\end{tabular}
group.

aNon-participating group; ${ }^{\mathrm{b}}$ Reference group; ${ }^{\mathrm{c}}$ Frequent participating $\mathrm{RG)}$

${ }^{*} p<0.05,{ }^{* *} p<0.01$ (Mantel-Haenszel $\chi^{2}$ test; NPG vs. RG and EPG vs.

TABLE 7. Age-adjusted proportions of subjects with past medical histories (Female)

\begin{tabular}{lcccccc}
\hline \multirow{2}{*}{ Group of participation } & \multicolumn{3}{c}{ Urban group } & \multicolumn{3}{c}{ Rural group } \\
\cline { 2 - 7 } & NPG $^{\mathrm{a}}$ & $\mathrm{RG}^{\mathrm{b}}$ & FPG $^{\mathrm{c}}$ & $\mathrm{NPG}$ & $\mathrm{RG}$ & FPG \\
\hline Hypertension & $19.6^{*}$ & 22.0 & 22.0 & $29.9^{* *}$ & 25.6 & 24.9 \\
Cerebrovasular disease & 0.8 & 0.5 & 0.4 & 0.7 & 0.6 & 0.4 \\
Heart disease & 8.4 & 9.1 & 7.7 & 9.4 & 10.0 & 10.4 \\
Diabetes & 4.3 & 4.1 & 3.9 & $4.9^{*}$ & 3.5 & 3.5 \\
Liver disease & 3.0 & 3.6 & 4.1 & 3.3 & 3.3 & 3.8 \\
Gastoro-duodenal ulcer & $4.7^{* *}$ & 7.1 & 8.5 & $5.4^{* *}$ & 8.4 & 9.0 \\
Gall stone & 3.4 & 4.3 & 4.2 & 3.5 & 2.6 & 3.3 \\
Appendicitis & 7.8 & 7.9 & $11.6^{* *}$ & 7.5 & 7.0 & $9.0^{*}$ \\
Tuberculosis & 5.6 & 4.6 & 5.4 & $3.6^{* *}$ & 1.0 & 1.0 \\
Pneumonia & 2.4 & 2.2 & 2.7 & $0.7^{*}$ & 1.8 & 1.2 \\
\hline
\end{tabular}

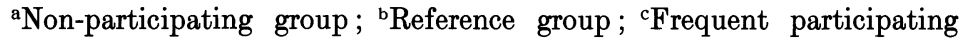
group. $\mathrm{RG)}$

${ }^{*} p<0.05,{ }^{* *} p<0.01$ (Mantel-Haenszel $\chi^{2}$ test; NPG vs. RG and FPG vs. 
TABLE 8. Stepwise regression analysis in relationship between frequency of participation and lifestyle

\begin{tabular}{|c|c|c|c|c|}
\hline & $\begin{array}{l}\text { Independent } \\
\text { variables }\end{array}$ & $\begin{array}{l}\text { Standardized regression } \\
\text { coefficients }\end{array}$ & T-value & $\mathrm{R}$ square \\
\hline \multirow[t]{3}{*}{ Urban (male) } & Age & -0.033 & $-2.393^{*}$ & 0.184 \\
\hline & Cancer $(\mathrm{F})^{\mathrm{a}}$ & 0.034 & $2.544^{*}$ & \\
\hline & Smoking & -0.065 & $-4.786^{* *}$ & \\
\hline \multirow[t]{5}{*}{ Urban (female) } & Age & 0.030 & $2.390^{*}$ & 0.229 \\
\hline & GDUb & 0.029 & $2.307^{*}$ & \\
\hline & Cancer(F) & 0.053 & $4.205^{* *}$ & \\
\hline & Cancer $(\mathbf{M})^{\mathrm{c}}$ & 0.077 & $6.091^{* *}$ & \\
\hline & Smoking & -0.049 & $-3.902^{* *}$ & \\
\hline \multirow[t]{7}{*}{ Rural (male) } & Age & 0.044 & $2.644^{* *}$ & 0.265 \\
\hline & $\mathrm{GC}(\mathrm{F})^{\mathrm{d}}$ & 0.055 & $3.291^{* *}$ & \\
\hline & Cancer(M) & 0.041 & $2.176^{*}$ & \\
\hline & $\mathrm{GC}(\mathrm{M})^{\mathrm{e}}$ & 0.038 & $2.025^{*}$ & \\
\hline & Milk & 0.111 & $6.433^{* *}$ & \\
\hline & Fruits & 0.037 & $2.120^{*}$ & \\
\hline & Smoking & -0.077 & $-4.544^{* *}$ & \\
\hline \multirow[t]{5}{*}{ Rural (female) } & Age & -0.063 & $-3.941^{* *}$ & 0.219 \\
\hline & Cancer $(\mathrm{F})$ & 0.051 & $3.211^{* *}$ & \\
\hline & $\mathrm{GC}(\mathrm{M})$ & 0.054 & $3.421^{* *}$ & \\
\hline & Milk & 0.110 & $6.892^{* *}$ & \\
\hline & Smoking & -0.074 & $-4.658^{* *}$ & \\
\hline
\end{tabular}

${ }^{\mathrm{a}}$ Father's history of cancers ; ${ }^{\mathrm{b}}$ Past history of gastroduodenal ulcer; 'Mother's histroy of cancers ; 'Father's history of gastric cancer; ${ }^{\mathrm{e}}$ Mother's history of gastric cancers.

$$
{ }^{*} p<0.05,{ }^{* *} p<0.01
$$

little differences in other past histories.

\section{Multiple regression analysis}

The results of the stepwise multiple regression analysis by sex and area are shown in Table 8. The independent variables induced for all subgroups were age, parental histories of cancers and smoking. The estimated coefficients for parents' histories of cancer were positive and those of smoking were negative among all the subgroups, indicating that there was consistency of association between either of the independent variables, parental histories of cancer and smoking, and frequency of participation. The directions of the estimated coefficient for age were not consistent in each subgroup, for example, it was negative for the male urban subgroup but positive for the female urban subgroup. In addition to these three variables milk consumption was induced in the rural groups of both sexes. Square of multiple regression coefficient $\left(\mathrm{R}^{2}\right)$ was nearly 0.2 in each subgroup. 


\section{Discussion}

In this study the subjects were classified into three groups according to frequency of participation in the screening program for stomach cancer during the last 5 years ; i.e., the NPG, the RG and the FPG consisted of the subjects whose frequencies were $0,1-3$ and 4 or 5 , respectively. This classification is based upon the results of our case-control study of advanced stomach cancer, which showed that yearly participation was most effective because the odds ratios of intervals from the last participation were 0.34 for 1 year, 0.74 for 2 years, 0.73 for 3 years, 1.05 for 4 years and 1.00 for 5 years or over (Fukao et al. 1987). This results suggest that the screening program is the most effective in the FPG. On the contrary, the effectiveness must be threatended by the NPG. In this study the characteristics of these two extreme groups were compared with the rest subjects (RG). Several investigations have been reported on the characteristics of participants in screening programs for cancer (Kuller and Tonascia 1970 ; Ogawa et al. 1978; Kato et al. 1986, 1987), but the present report is probably the first to evaluate them by categorizing subjects according to participation frequencies. Participants of cancer screening programs are known to have self-selection bias; i.e., they have some awareness of risks for the disease and some knowledge for its prevention (Shapiro 1977; The Coronary Drug Project Research Group 1980; Morrison 1985). This bias is thought to overestimate the effectiveness of cancer screening. The present study indicates that not only the group of participants had self-selection bias stated above, but also the group of non-participants had self-selection bias in the inverse direction. For example the intake of milk and green-yellow vegetables, both of which are regarded as protective factors for stomach cancer (Hirayama 1971; Trichopoulos et al. 1985 ; Kono et al. 1988) was less in the NPG and more in the FPG. Moreover, the age-adjusted proportions of present smokers, who are at higher risk because smoking were regarded as one of the risk factors in several epidemiologic surveys (Hirayama 1971; Tajima and Tominaga 1985; Kono et al. 1988), were higher in the NPG and lower in the FPG.

Smoking habit was found one of the strongest predictors of frequency of participation because it was induced for all subgroups in a stepwise multiple regression analysis. Kato et al. also reported that the proportion of smokers was lower among participants than among non-participants (Kato et al. 1986). This result and ours indicate that consistency of association between smoking and participation is found in different areas in Japan.

Although the age-adjusted proportions of the subjects consuming milk everyday were lower in the NPG and higher in the FPG than in the RG among all the subgroups, the variable of milk consumption was induced only for the rural groups of both sexes in the stepwise multiple regression analysis. It is difficult to explain the reason for the rural-urban difference in the relationship between milk consumption and frequency of participation. The age-adjusted proportions of the 
subjects frequently consuming green-yellow vegetables were lower in the NPG and higher in the FPG among all the subgroups, whereas the variable of consumption of these vegetables was not induced in the stepwise regression analysis, indicating that it would not be such a strong predictor in the case of adjusting other factors.

The results, both the comparison of the age-adjusted proportions and the stepwise multiple regression analysis, showed that the relationship between parental histories of cancers and frequency of participation was remarkably strong, suggesting that parental histories of cancers intensely motivated paticipation in cancer screening. The past history of gastro-duodenal ulcer may be also a possible factor to motivate participation, because people with this history may participate more frequently in the examinations to know the course of their ulcers. This variable, however, was induced for only the female urban group in the stepwise multiple regression analysis.

In the model of stepwise regression analysis, the square of multiple regression coefficient ( $\mathrm{R}$ square) was rather small (nearly 0.2 in each subgroup), indicating that most of the variability in frequency of participation could not be accounted for the variables studied in this analysis. As socioeconomic status and personality will possibly be important variables, a further study including these variables is proceeding.

This study revealed that there are two extreme groups in the population, i.e., one group (FPG) in which subjects frequently participate in screening, take more protective factors and smoke less, and an other group (NPG) in which subjects rarely participate in screening, take less protective factors and smoke more. As there is not much doubt that the latter group is regarded as a high risk group of stomach cancer, subjects of this group should be a reasonable target for cancer prevention. Approaching this group not only to stimulate to participate in the screeing but also to converse the awareness of health is essential.

\section{References}

1) Fukao, A., Hisamichi, S. \& Sugawara, N. (1987) A case-control study on evaluating the effect of mass screening on decreasing advanced stomach cancer. J. Gastroenterol. Mass Survey, 75, 112-116. (in Japanese)

2) Hirayama, T. (1971) Epidemiology of stomach cancer. Gann Monogr. Cancer Res., 11, 3-19.

3) Hirayama, T., Hisamichi, S., Fujimoto, I., Ohsima, A. \& Tominaga, S. (1985) Screening for gastric cancer. In: Screening for Cancer, edited by A.B. Miller, Academic Press, Orland, pp. 367-376.

4) Hisamichi, S., Sugawara, N. \& Fukao, A. (1988) Effectiveness of gastric mass screening in Japan. Cancer Detect. Prev., 11, 322-329.

5) Ikeda, M., Watanabe, T., Hisamichi, S., Shimizu, H., Fujisaku, S., Ichinowatari, Y., Ida, Y., Suda, M. \& Kato, K. (1986) Upper respiratory symptoms resumably due to studded tire-generated dust. Environm. Int., 12, 505-511.

6) Kato, I., Tominaga, S. \& Naruhashi, H. (1986) Characteristics of participants of stomach cancer screening test. Jpn. J. Public Health, 33 749-753. (Japanese with English abstract) 
7) Kato, I., Tominaga, S. \& Matsuoka, I. (1987) Characteristics of participants of uterine cancer screening test. Jpn. J. Public Health, 34, 748-754. (Japanese with English abstract)

8) Kono, S., Ikeda, M., Tokudome, S. \& Kuratsune, M. (1988) A case-control study of gastric cancer and diet in northern Kyushu, Japan. Jpn. J. Cancer Res., 79, 10671074.

9) Kuller, L. \& Tonascia, S. (1970) Commission on chronic illness follow-up study: Comparison of screened and nonscreened individuals. Arch. Environ. Health, 21, 656665 .

10) Morrison, A.S. (1985) Screening in Chronic Disease, edited by A. S. Morrison, Oxford University Press, Oxford, pp. 3-20.

11) Nakatsuka, H., Kasahara, M. \& Watanabe, T. (1988) Urban-rural differences in food habits in north-eastern Japan. Ecol. Food Nutri., 21, 77-87.

12) Ogawa, H., Aoki, K., Shimizu, H., Kuroishi, T. \& Tominaga, S. (1978) A medicosocial psychological study on attitude toward stomach cancer. Jpn. J. Public Health, 25, 421-436. (Japanese with English abstract)

13) Ohshima, A., Hirata, N., Ubukata, T., Umeda, K. \& Fujimoto, I. (1986) Evaluation of a mass screening program for stomach cancer with a case-control study design. Int. J. Cancer, 38, 829-833.

14) Shapiro, S. (1977) Evidence on screening for breast cancer from a randomized trial. Cancer, 39, 2772-2782.

15) Tajima, K. \& Tominaga, S. (1985) Dietary habits and gastro-intestinal cancers: A comparative case-control study of stomach and large intestinal cancers in Nagoya, Japan. Jpn. J. Cancer Res., 76, 705-716.

16) The Coronary Drug Project Research Group (1980) Influences of adherence to treatment and response of cholesterol on mortality in the Coronary Drug Project. N. Engl. J. Med., 303, 1038-1041.

17) Trichopoulos, D., Ouranos, G., Day, N. E., Tzonou, A., Manousos, O., Papadimitriou, C.H. \& Trichopoulos, A. (1985) Diet and cancer of the stomach; a case-control study in Greece. Int. J. Cancer, 36, 291-297. 